\title{
A poética dos desvios na montagem visual de Îcaro Lira
}

Por: Eduarda Kuhnert ${ }^{1}$ 
Não tenho nada a dizer. Somente a mostrar. Não surrupiarei coisas valiosas, nem me apropriarei de formulações espirituosas. Porém, os farrapos, os resíduos: não quero inventariá-los, e sim fazer-lhes justiça da única maneira possível: utilizandoos. (BENJAMIN, 2009, p.502)

Em meio a recortes de jornais, imagens, pedras, documentos, reproduções de obras de arte e lascas de árvores, a obra do artista visual Ícaro Lira vira ao avesso os materiais para mostrar o que escondem as sombras dos acontecimentos históricos. Como opera Walter Benjamin em sua montagem literária no livro Passagens (1940), Ícaro cita sem usar aspas: enfrenta o arquivo na sua materialidade para submetê-lo à reflexão.

Nascido em Fortaleza, Ícaro tem uma ampla atuação enquanto artista: exerce atividades como editor, produtor, curador, mediador, pesquisador e outras, que, uma vez articuladas, fazem parte da sua produção artística. Em projetos como Cidade Partida, Museu do Estrangeiro e Campo Geral, os vestígios recolhidos durante as pesquisas de campo são trabalhados na montagem, seja ela editada em publicações ou disposta em espaços expositivos, como Paço das Artes e Oficina Cultural Oswald de Andrade. Atualmente, sua produção tem se desdobrado em um conjunto de ações, não mais concluídas em objetos artísticos, como ocorreu durante a residência artística na Ocupação Hotel Cambridge, situada na região central de São Paulo, em 2016.

Há cerca de cinco anos, Ícaro Lira tem aberto dossiês sobre atos políticos e históricos brasileiros, como a Guerra de Canudos e o fluxo migratório no país. Em seu método de trabalho, a história é vista com uma lupa e a atenção é dada ao que os acontecimentos revelam de minúsculo e singular sobre o passado. Seus personagens são os seres anônimos da história e os rastros deixados por eles, que o faz pensar o real por um viés ficcional, escapando de um saber fixo. Aqui, a história dos historiadores e a história dos artistas são colocadas em um mesmo regime de sentido: seus signos são equivalentes, mas ordenados de forma distinta a fim de construir efeitos no presente.

Como uma costura de fragmentos das narrativas não-oficiais, Ícaro desmonta e remonta objetos destinados ao esquecimento e dá acesso a uma escrita da história que não teme partir de um olhar perspectivo. Seus projetos envolvem o trabalho no arquivo, que desnuda o real, o reaviva ao recusar o indizível e se apropria dos documentos, que são mudos, surdos e cegos, para que contem uma história. Em outras palavras, o historiador francês Marc Bloch acrescenta: "Os textos ou os documentos históricos só falam quando sabemos questioná-los." (BLOCH apud LEANDRO, 2012, p.9). Ícaro interroga as abordagens tradicionais da história por meio de uma colagem dos materiais coletados, uma produção de encontros que os ressignifica.

Uma das primeiras operações do processo de montagem do material de arquivo é a definição de parâmetros para a criação de uma série. A retirada dos documentos de uma série institucionalizada para a construção de outra é instaurada por uma

1 eduardakuhnert@gmail.com 
ordem que só existe no campo da linguagem, visto que o lugar-comum que os une é a própria montagem. Em As palavras e as coisas, o filósofo francês Michel Foucault abre o livro com uma série estabelecida pelo escritor argentino Jorge Luis Borges, no qual são agrupados animais que não tem relação evidente entre si em uma suposta enciclopédia chinesa, compondo uma nova ordem:

O impossível não é a vizinhança das coisas, é o lugar mesmo onde elas poderiam avizinhar-se. Os animais "i) que se agitam como loucos, j) inumeráveis, k) desenhados com um pincel muito fino de pêlo de camelo" - onde poderiam eles jamais se encontrar, a não ser na voz imaterial que pronuncia sua enumeração, a não ser na página que a transcreve? Onde poderiam eles se justapor, senão no não lugar da linguagem? (FOUCAULT, 2007, p.XI)

As pedras que pesam em cima de livros, os lenços de tecido colorido e a reprodução do quadro $A$ Redenção de Cam (1895), que fazem parte da série Campo Geral (2015), revelam as heterogeneidades e anacronismos possíveis na unidade de um conjunto. Os jogos de aproximação e oposição presentes na lista de Borges também caracterizam a montagem poética de Ícaro. Sua proposta de agrupamento religa tempos históricos em um gesto político de desierarquização iconográfica, ao articular ícones da história da arte com elementos do cotidiano. Os documentos, imagens e objetos não existem mais por si próprios, mas sempre em relação a outros elementos e, em larga escala, a outras séries da sua produção artística.

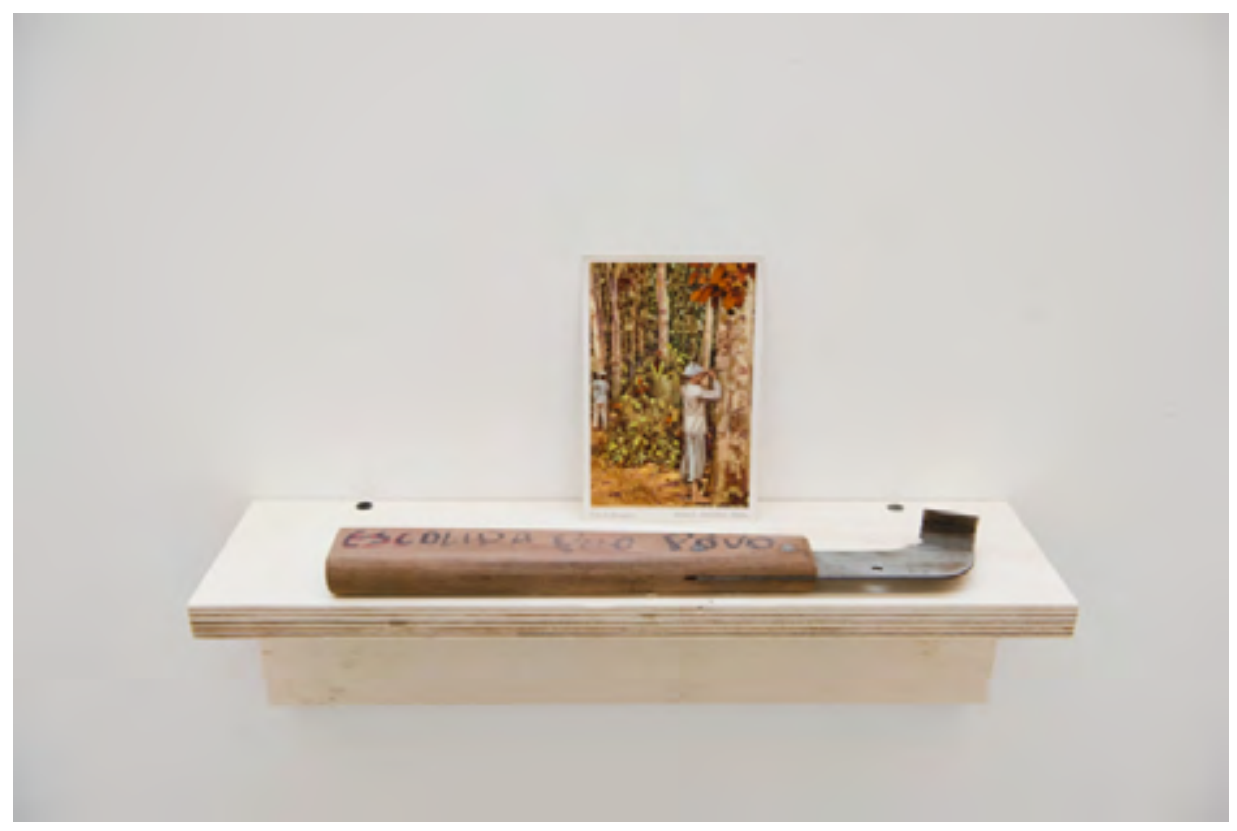

Campo Geral - Central Galeria de Arte - São Paulo (2015). Foto: Isadora Brant 
Em texto², você afirma que as suas exposições têm estruturas similares a pequenos museus. Se compreendermos esse lugar emblemático que é o arquivo como a possibilidade de construção de uma narrativa, ou seja, como o ordenamento de materiais segundo critérios estabelecidos, seria possível afirmar que seus trabalhos, como o Museu do Estrangeiro, constituem um arquivo?

Sim, eu acho que o Museu do Estrangeiro é um arquivo. Assim como Cidade Partida e Campo Geral - este último uma pesquisa realizada durante cerca de quatro anos sobre os campos de concentração no Ceará - são também arquivos, mas estão em constante modificação. Um exemplo disso é o projeto que participei, idealizado pela Ana Pato, chamado Arquivo e Ficção, realizado desde a 3a Bienal da Bahia, em 2014. A proposta da Ana era transformar o Arquivo Público do Estado da Bahia, que é um dos acervos mais importantes do Brasil depois da Biblioteca Nacional. O prédio foi construído pelos jesuítas, ficou abandonado durante muito tempo, ocupado como leprosário e posteriormente transformado em Arquivo Público, reunindo todos os arquivos que estavam espalhados em Salvador. O espaço fica em uma área periférica da cidade, ao lado do cemitério onde eram enterrados os leprosos e são enterrados indigentes hoje em dia. Os encontros entre artistas, arquivistas, museólogos e pesquisadores aconteciam nesse lugar, que é muito forte, e a pesquisa era divulgada no Museu Estácio de Lima - uma instituição que estava fechada desde 2004, onde são mantidas apreensões da Polícia Militar, desde armas usadas na Guerra de Canudos até drogas e armas das penitenciárias do interior da Bahia, além de ter expostas as cabeças mumificadas de Lampião e Maria Bonita. Após esse período de encontros, o projeto permaneceu através de uma página de Facebook, que foi alimentada coletivamente e de forma colaborativa por todos os participantes, além de artistas e produtores. Esse projeto também é um arquivo, mas segue em constante modificação, falo isso porque muitas vezes o arquivo é visto como algo morto e parado. Já o Museu do Estrangeiro é um arquivo fictício, pois não existe. O projeto surgiu como uma tentativa de discutir sobre certas comunidades de imigrantes de São Paulo que percebi que não participam do arquivo, vamos dizer, oficial da cidade. O Museu da Imigração, no Brás, localizado no prédio onde funcionou a antiga Hospedaria Central - primeiro lugar que os imigrantes ficavam quando chegavam na cidade, um tipo de quarentena - apresenta somente a imigração europeia e um pouco da japonesa. Mas todos os outros grupos, como os nordestinos, coreanos ou bolivianos, não estão representados no museu. Assim, o meu trabalho aparece como uma resposta a isso, através da criação de um arquivo fictício sobre essas outras migrações. Além disso, o Museu do Estrangeiro discute o incentivo da imigração europeia pelo Estado brasileiro como um meio de embranquecimento racial do país, o que era compreendido como a consolidação de um país mais forte, segundo as noções étnicas desse contexto histórico. O trabalho surgiu em meio à intensa vinda de haitianos para o Brasil, por conta do terremoto e da criação do visto voluntário no país, além da discussão sobre a Minustah, a ocupação da ONU no Haiti, dirigida pelo exército brasileiro. $O$ arquivo do 
Museu do Estrangeiro continua crescendo. Durante o período da Residência Artística na Ocupação Cambridge, eu me aproximei muito do grupo de imigrantes palestinos e sírios, como o Issan, morador da ocupação, refugiado, professor de biologia e poeta. Essa experiência foi incorporada ao trabalho, através da criação de um arquivo sobre a questão do Nakba [termo em árabe que significa catástrofe e designa o êxodo palestino no momento da formação do Estado de Israel, em 1948], pois existem muitos museus sobre o Holocausto no mundo, inclusive no Brasil, mas não existe nenhum sobre o Nakba, nem mesmo na Palestina. Portanto, esse trabalho é um arquivo em constante construção, e agora se tornou uma construção colaborativa. Eu vou apresentar em breve o Museu do Estrangeiro no Videobrasil [20 Festival de Arte Contemporânea Sesc Videobrasil, exposição a ser realizada no Sesc Pompeia entre outubro de 2017 a janeiro de 2018] com um arquivo montado a partir da pesquisa sobre imigração, com várias colaborações e agenciamentos para a produção de obras e documentos com um grupo de pesquisadores e artistas imigrantes e refugiados: Isan Ahmad Issan, Kuta Ndumbu, Akon Patrick, Shambuyi Wetu, Louides Charles e Sara Ajlyakin. Estou produzindo uma peça sonora, o que seria algo mais próximo de uma obra, também construída com todas essas vozes e editada por diversas mãos. Além disso, é interessante pensar na questão museológica relacionada ao trabalho com o arquivo, pois eu lido com o arquivo, mas não tenho esse cuidado da conservação que museólogos ou arquivistas teriam. Por isso, a publicação acaba se tornando um registro, como outro arquivo, e possibilita formas de circulação do trabalho para lugares além do espaço expositivo.

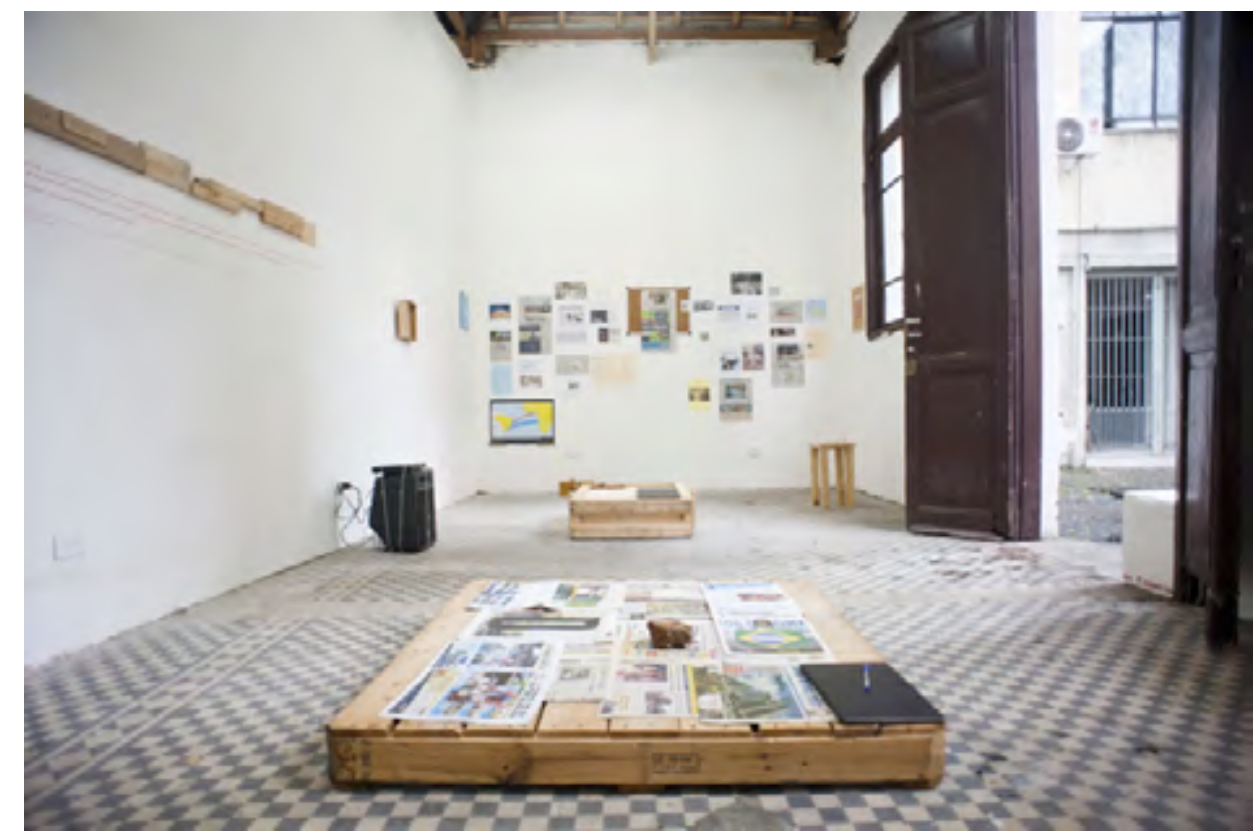

Museu do Estrangeiro - Oficina Cultural Oswald de Andrade - São Paulo (2015). Foto: Isadora Brant 
Um aspecto que chama atenção na sua produção é a montagem, que pode ser entendida como uma tomada de posição em relação ao material de arquivo, seja ele documento, imagem ou objeto. Isso acontece desde a seleção até a disposição do material. Quais são os seus critérios para realizar essa montagem?

A montagem é um momento muito importante do trabalho. Existem três momentos da realização da obra: o primeiro é a pesquisa; o segundo é a viagem, que é o trabalho de campo, para mim é muito importante fazer a visita in loco; e o terceiro momento é a montagem. Em regra, eu não tenho ateliê. Salvo alguns episódios específicos de residência que tive um, eu sempre trabalhei em casa mesmo, com uma mesa e uma parede. Na verdade, eu preciso de pouco espaço e nunca tive vontade de ter ateliê. Eu produzo coisas pequenas, e quando são grandes, como um mobiliário, por exemplo, são projetos em colaboração com algum amigo. Então, muitos trabalhos são realizados mesmo durante o processo de montagem, que não tem um ponto final, o que cria uma dificuldade para museus e galerias. A seleção dos materiais tem um recorte com uma diretriz, uma tomada de opinião sobre o assunto. Mas essa montagem é contínua, assim como a pesquisa é contínua, por isso os trabalhos vão se modificando também. Eles não tem uma forma final, pode ter uma forma hoje e daqui a duas semanas o trabalho pode deixar de existir assim pois eu juntei duas coisas para transformar em uma terceira. Ou seja, a ideia é que ele não acabe. Esse movimento me interessa muito. Isso cria algumas dificuldades de circulação do trabalho, eu faço poucas exposições coletivas, os meus projetos são longos. Cidade Partida, Campo Geral e Museu do Estrangeiro, que foram as últimas exposições que fiz, são trabalhos que não são uma coisa, mas uma série: vídeos, livros, áudios, objetos, documentos. Então, o trabalho não é um objeto na parede ou uma peça isolada, mas a articulação entre todas as peças, pois um elemento dá sentido ao outro. Essa forma de trabalhar se inicia na experiência que tive na Bienal da Bahia e se intensificou na residência da Ocupação Cambridge. Assim, o meu trabalho deixou de ser objetual. Nos últimos dois anos eu quase não tenho produzido coisas físicas, como objetos, fotos e vídeos, mas tenho articulado e criado uma série de ações e atividades. Desde o início, a minha intenção na Ocupação Cambridge era ter uma atuação ali dentro, em vez de produzir objetos que entrariam no mercado da arte. Então, a gente organizou desde uma oficina de publicação com a Dulcineia Catadora, um coletivo de mulheres catadores de papel, até uma clínica de psicanálise, um cineclube, uma série de seminários com pesquisadores como o Peter Pál Pelbart, Raquel Rolnik e outras pessoas que poderiam criar algum tipo de diálogo com o movimento de moradia. Agora eu estou fazendo o mesmo nesse projeto para o Videobrasil, não estou produzindo uma obra, mas convidei artistas e pesquisadores para articular junto com eles o que poderia ser essa exposição, como se fosse uma exposição dentro da exposição. E a ideia de montagem permanece, é uma atividade próxima de uma curadoria. 


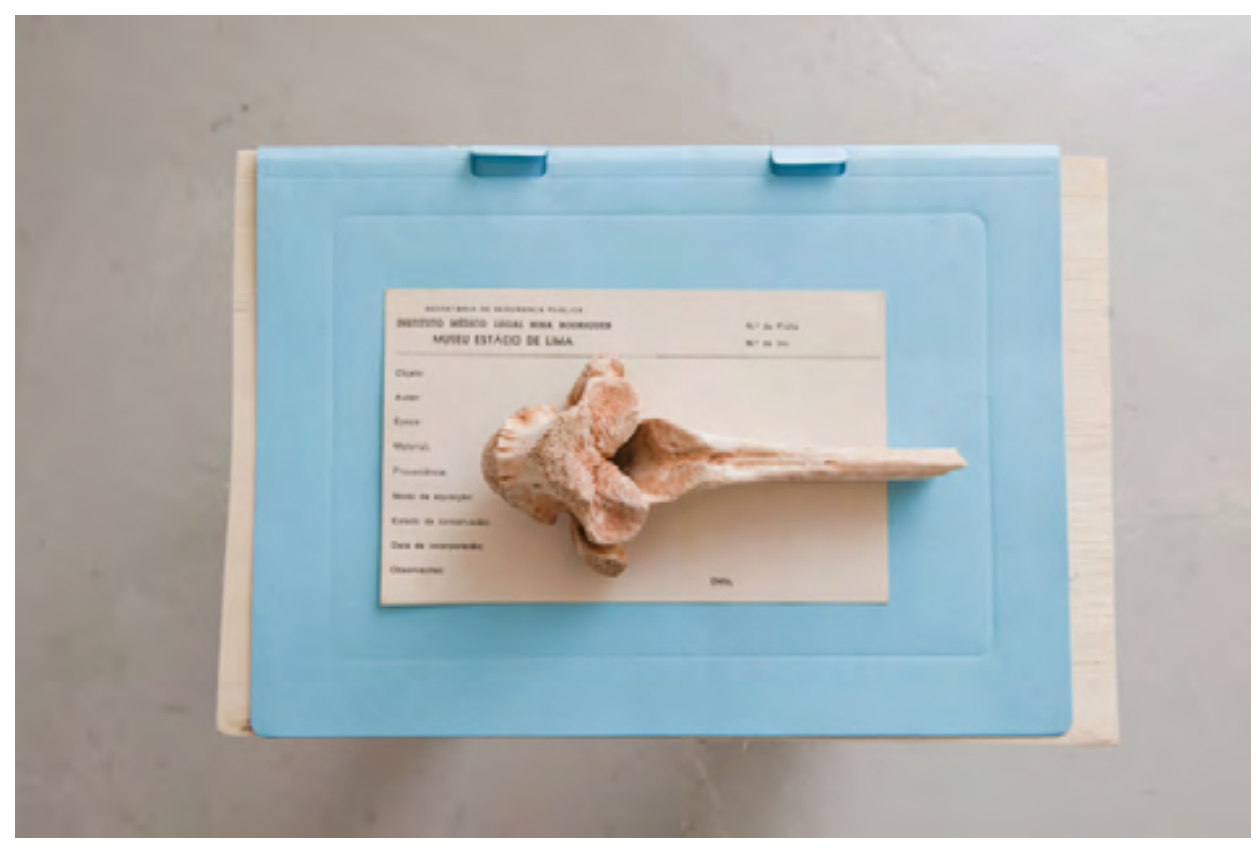

Campo Geral - Central Galeria de Arte - São Paulo (2015). Foto: Isadora Brant

\section{É visível em projetos já mencionados antes, como Cidade Partida e Campo Geral, uma montagem que coloca em choque diferentes temporalidades. Como você pensa o método dialético na montagem?}

Existem possibilidades que são da liberdade do artista que, muitas vezes, antropólogos e historiadores não têm. Por exemplo, eu reuni em Cidade Partida um jornal da época da Guerra de Canudos, que é um documento simbólico, lado a lado com uma matéria sobre o Amarildo [Amarildo Dias de Souza, ajudante de pedreiro, desaparecido desde 2013 após ter sido detido por policiais militares no Rio de Janeiro]. Essas conexões são importantes, pois criam uma situação de ruído, mesmo que pareçam aleatórias algumas vezes. Essa disposição faz o espectador produzir suas próprias conexões, por isso eu tento deixar um pouco em aberto para que cada um possa captar alguma coisa. Alguns vão captar mais, outros menos. Nesse sentido, eu acho que o caminho que o espectador faz no espaço expositivo também influencia o seu entendimento. Existem vários caminhos possíveis e, por consequência, muitas conexões possíveis. Isso também está presente no Museu do Estrangeiro. Eu trouxe muitas imagens da Revolução Haitiana para esse trabalho, ao mesmo tempo em que coloquei imagens da situação dos haitianos em São Paulo e exemplares de jornais que usavam termos muito ofensivos como "invasão" ou "surto" para falar dessa imigração. Então, me interessa utilizar da dialética para criar esses contrapontos. Como se fosse uma linha, que vai e volta no tempo. Por exemplo, a gente está vendo como existe um movimento cíclico que parece estar se repetindo com o impeachment/golpe ou no caso do fechamento da exposição "Queermuseu", em Porto Alegre. Como aquela famosa frase: "A história se repete como farsa". 
No texto Sobre o conceito de história, o filósofo alemão Walter Benjamin apresenta o seu método de escrita da história como o ato de escová-la a contrapelo, que busca analisar os vestígios e os restos dos acontecimentos históricos, como você faz ao trazer elementos da narrativa não-oficial da Guerra de Canudos, por exemplo.

Sim, é bem isso mesmo. As narrativas oficiais são construções também. Por exemplo, Antônio Conselheiro é muitas vezes visto como louco e até a sua iconografia conduz para essa ideia, e não como um líder popular, que seria mais próximo do que ele foi mesmo.

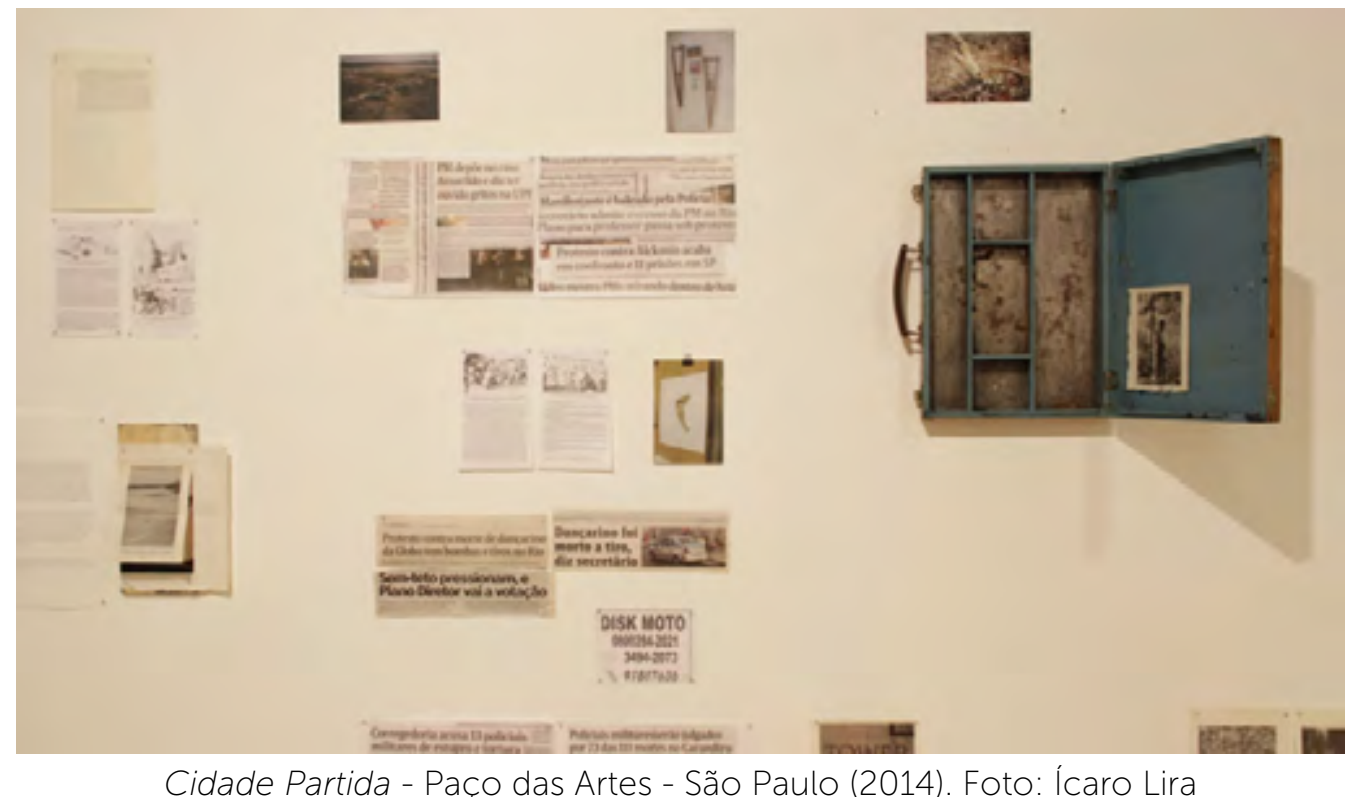

Além disso, eu vejo também um aspecto anacrônico na montagem dos seus trabalhos, uma vez que existe um presente que se interessa por esses períodos da história brasileira analisados nos seus trabalhos.

Pois é, no momento de produção do Cidade Partida, estava recente o episódio em Pinheirinho, em São Paulo, que foi um massacre e ninguém se lembra mais [Em 2012, a Polícia Militar de São Paulo realizou uma violenta operação de reintegração de posse na comunidade, em São José dos Campos]. Logo em seguida, teve o caso do Amarildo, que estava se falando muito, apesar de as UPPs [Unidades de Polícia Pacificadora] serem vistas como um grande sucesso naquela época. Desde a montagem de Cidade Partida, a Revolta da Vacina é outro acontecimento que tenho interesse em me aprofundar. Foi o momento da reforma urbana do Rio de Janeiro, feita pelo prefeito Pereira Passos, que transformou o Rio em uma cidade segregada, com o "Bota-Abaixo", o fim dos cortiços e a construção da Avenida Rio Branco. E se relaciona muito com a gestão do Eduardo Paes [prefeito do Rio de Janeiro entre 2009 e 2016], que teve o Passos como inspiração para o Porto Maravilha. Ou seja, são repetições de uma mesma situação. 
A publicação Erramos, que discute os fatos da história brasileira recente através da montagem de manchetes de jornais sobre as manifestações de 2013, parece se relacionar com uma característica própria ao arquivo, que é se apresentar como excesso e também como falta. É uma montagem densa que expõe a narrativa massificante da grande mídia, mas através da qual também é possível ler nas suas entranhas o que não foi escrito sobre esse acontecimento.

Sim, o que não foi dito e o que não foi contado. E às vezes isso diz muito mais. Eu fiz essa publicação em 2013, com manchetes das manifestações na época pré-Copa, e ela acabou entrando na montagem de Cidade Partida no Paço das Artes. Depois eu acabei fazendo vários exemplares e distribuí.

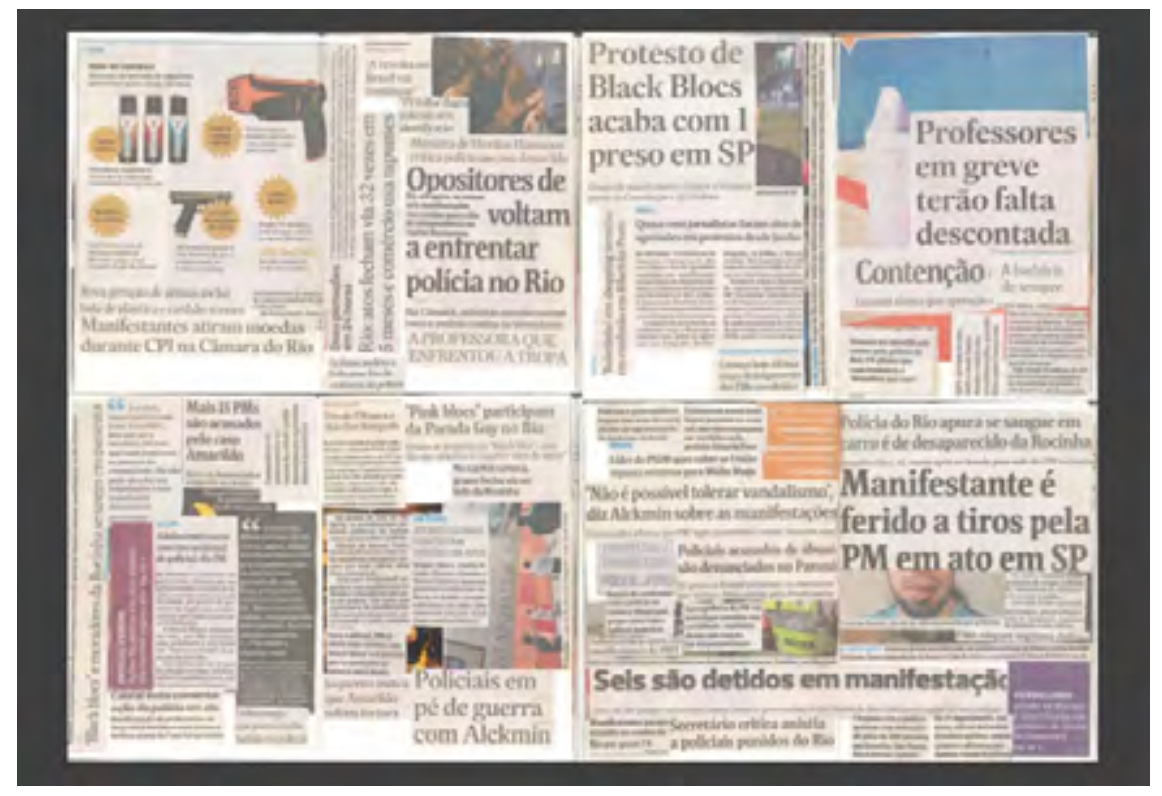

Erramos - Publicação (2013)

Eu vejo que os seus trabalhos demandam uma disposição pela demora, seja no momento da sua produção ou durante a ida na exposição, no encontro com os materiais dos seus projetos. Uma demora que foge do regime de tempo e produção contemporânea, o que também caracteriza o trabalho em um arquivo.

Sim, o trabalho no arquivo demanda um olhar cuidadoso. Essa busca por pensar em outras formas que o trabalho pode ocupar me fez ser convidado para falar em algumas ocasiões. Eu vejo uma importância nesses momentos, são tão importantes quanto apresentar as obras em um espaço expositivo, as publicações ou o material disponível na internet. Esses encontros são fundamentais para a construção do trabalho. Mas, ao mesmo tempo, o meio artístico mais consolidado também dificulta essa atuação, porque surgem muitas demandas de produção. Então, se tornou mais difícil ter esse tempo. Por exemplo, eu fui para Canudos sete vezes durante três anos, mas hoje em dia não conseguiria fazer isso de novo. Me interessa também pensar a escala do trabalho. Eu tenho trabalhado muito com publicações nos últimos 
anos. Após o fim da residência na Ocupação Cambridge, eu trabalhei durante um ano na publicação sobre esse projeto, fazendo encontros com moradores, artistas colaboradores e editores. É um tempo muito estendido que, na verdade, não acaba. De certa forma o projeto sobre Canudos se encerrou, mas por causa dessa pesquisa eu me interessei pela Revolta da Vacina e isso vai se tornar um trabalho em algum momento. A pesquisa sobre a questão das imigrações no Nordeste me levou até a produção do Museu do Estrangeiro. Ou seja, são trabalhos que apresentam desdobramentos e ramificações. A produção é como uma coisa só, mas com várias atuações. Como você disse, os meus trabalhos tem a ver com essa ideia do Walter Benjamin de escovar a história a contrapelo, sobre o que não foi dito ou mal contado. Essas questões sociais sempre estiveram muito próximas da minha vida. Então, eu mantive esses interesses quando comecei a trabalhar com arte. Como eu sou migrante, busquei histórias que me acompanham, pois Canudos é uma presença muito forte na minha história pessoal. Mas o que liga a minha produção é o interesse por essas histórias esquecidas e apagadas oficialmente pelo Estado. Eu acho que o trabalho do artista tem que possuir algum sentido para além da produção de objetos, mas uma produção de conceitos e outras formas de atuação.

\section{Referências}

BENJAMIN, W. Obras escolhidas I: Magia e técnica, arte e política. 8a edição. São Paulo: Editora Brasiliense, 2012.

BENJAMIN, W. Passagens. Belo Horizonte: Editora UFMG, 2009

FOUCAULT, M. As palavras e as coisas: uma arqueologia das ciências humanas. 9a edição. São Paulo: Martins Fontes, 2007.

LEANDRO, A. Desvios de imagens, ontem e hoje: de Debord a Coutinho. In: Revista da Associação Nacional dos Programas de Pós-Graduação em Comunicação - E-compós. Brasília, 2012 